\title{
Publicações Recebidas
}

Recebemos e agradecemos as diversas publicações, que, até o presente trimestre, chegaram à nossa redação.

Américas - Desta revista, temos os volumes de $n^{\circ} 3$, referente a março dêste ano, e o $\mathrm{n}^{\circ} 4$, referente a abril, ambos do Ano XVII da mesma publicação, sendo o excmplar de abril especialmente dedicado ao $75^{\circ}$ aniversário do Sistema Interamericano. Sua capa apresenta a manchete "Alicerces para o Amanhã", que trata do artigo de fundo assinado pelo Secretário-Geral da OEA, a respeito desta instituição, nesse ano em que transcorre a passagem de seu terceiro lustro de existência. Muitos artigos mais focalizam - essa mesma efeméride, apresentando pormenores da vida organizacional e politica dêsse órgão.

Recebemos mais outro volume de $\mathrm{n}^{2} 5$, pertencente a maio do corrente ano, em que há em sua capa uma tela do pintor El Greco, representativa de uma ceia que se intitula Jantar na Casa de Simão, e muitas mais aparecem nesse vo lume, tôdas do mesmo autor e pertencentes ao mesmo dono, recentemente falecido, Oscar B. Cintas descobertas após sua morte, em 1957. O colecionador foi embaixador de Cuba.

Outro a tigo nos fala de música folclórica dos Estados Unidos, por Sarah Gertrude Knott, fundadora e diretora dos Festivais Nacionais de Folclore mostrados no mesmo artigo. Cita êle que o I Festival foi realizado em 1934 .

Arquivos da Faculdade de Higiene e Saúde Pública - Este boletim é o órgão oficial da Faculdade de Higiene e Saúde Pública da Universidade de São Paulo, e é editado, semestralmente, sob a orientação da "Comissão de Biblioteca" da mesma. Seus artigos versam todos sôbre patologia, e saúde, ab angendo tudo quanto se relacione com tais matérias. Recebemos, neste trimestre o volume 18 , de ns. $1 / 2$, de janeiro-dezembro de 1964 , proveniente da cidade de Juqueri, em Franco da Rocha, no Estado brasileiro de São Paulo.

Arquivos do Departamento de Assistência a Psicopatas de São Pauto - O número único do volume XXVIII, referente a janeiro-dezembro de 1962, foi editado no Estado de S. Paulo. Esta é uma publicação do Corpo Clinico do Hospital de Juque-i, pertencente à Secretaria da Saúde Pública e Assistência Social do Estado de São Paulo, no Brasil. Seu primeiro artigo intitula-se "Fenômenos de Expansão do EU", cujo autor é Alberto Lyra, que também apresenta neste número, Misticismo e Psiquiatria". Aparecem, ainda, de autoria de Paulo Praletti, que é o fundador e já foi o $1^{2}$ Secretário do Departamento de Psiquiatria do Centro de Estudos Franco da Rorha, sob o título "A Psiquiatria em São Paulo", integra do discurso proferido em 9 de fevereiro de 1962 , na Associação Paulista de Medicina. Mais adiante, a revista publica outro discurso do mesmo orador, já agora, proferido na $122^{\circ}$ Reunião Extraordinária do Centro, a 9 de outubro de 1962, por ocasiáo do $20^{\circ}$ aniversário de fundaçáo do referido Centro, e também, o discurso do mesmo orador, 
despedindo-se da presidência do Centro, após 5 anos de exercício, com 3 mandatos consecutivos, em solenidade realizada no auditório da Associação, a 4 de dezembro de 1962 , durante a qual, teve oportunidade de agradecer a todos aquêles que com êle colaboraram em prol do movimento renovador da Psiquiatria, em São Paulo. Atas das sessões ordinárias do Centro aparecem ai, também, inclusive Noticias do Centro e outras notícias, finalizando êste volume.

Boletim Técnico do IPEAN - O Instituto Agronômico do Norte, reedita suas publicações, em Belém do Pará, apresentando dados estatísticos de diversos assuntos que são estudados pelo mencionado Instituto, como po: exemplo, o presente volume, que trata do Levantamento de Reconhecimento Detalhado dos Solos da Estrada de Ferro do Amapá; é a publicação de $n * 45$, de 1964. Denomina-se o referido Instituto, atualmente, Instituto de Pesquisas e Experimentação Agropecuárias do Norte.

Brasil Açucareiro - Esta publicação é editada pelo Serviço de Documentação do IAA e se destina ao trato dos problemas da agro-indústria canaviei a. Ela é normalmente iniciada por uma seção que se intitula "Notas e Comentários" e apresenta, além de vários artigos que debatem os últimos acontecimentos relativos ao assunto de que trata, os últimos atos do Poder Executivo e também, as Resoluçôes, Julgamentos e Atas da Comissấo Executiva do Instituto, bem como, os atos do Presidente da autarquia. Termina sempre com bibliog ־afia especifica dessa matéria. Temos em nossas mãos os presentes exemplares: do Ano XXXIII, os $\mathrm{n}^{\mathrm{s}} 1$ - volume LXV de janeiro de 1965; o $\mathrm{n}^{\circ} 2$, de fevereito de 1965; e $n^{\circ} 4$, volume LXV, de abril do mesmo ano, editados no Instituto do Açúcar e do Alcool, no Brasil.

Bulletin Analytiaue de Documentation Polit'que, Economique et Sociale
Contemporaine - $\mathrm{O}$ órgăo de cultura francesa "Fondation Nationale des Sciences Politiques", funciona sob a direção de Jean Meyriat, com o concurso do Centro Nacional de Pesquisas Cientificas, publica mensalmente êste boletim. Dedica-se tal revista a divulgar resenhas ali elaboradas, das publicações recebidas durante o trimestre, quer francesas, quer internacionais, as quais versam sôbre os assuntos que constituem os objetivos do boletim, conforme seu próprio nome indica. Recebemos os volumes relativos ao 19 e année, número 12 de 1964; mais o $\mathrm{n}^{\circ} 1$ do $20^{\circ}$ anneé, do ano de 1965 , e também, o $n^{*} 2$ - 20 année, do mesmo ano, elaborados em Paris, France.

Ciencias Administrativas -.. "Primera revista argentina de la especialidad". Revista do Instituto Superior de Ciências Administrativas da $\mathrm{Fa}$ culdade de Ciências Econômicas, Universidad Nacional de la Plata, na República Argentina. Em seu sumário que vem colocado como fêcho de tôda matéria que a revista divulga, se encontram artigos que debatem, com exclusividade, temas de Administração Pública e Privada, bem como, de ciência da administração e assuntos correlatos, tais como: comunicações, produção, administração hospitalar, orçamentária, etc. Este exemplar apresenta os planos de estudo, as o:ientações atuais no ensino da economia, e sôbre outras matérias mais, que são conclusões tiradas por D. Miguel Angel Rodrigues, a respeito da III Jornadas Rioplatenses de Ciências Econômicas en Punta del Este. O Instituto Superior de Ciências Administrativas da Argentina, é tambẻm, membro coletivo do Instituto Internacional de Ciências Administrativas, de Bruxelas, na Bélgica.

Companhia Hidrelétrica do São Francisco - A Comissão Executiva do Acôrdo CHESF-SENAI, apresenta: I - Relatório do Ano II, relativo ao biênio 1963-64 julho de 1963 a egôsto de 1964; 
II - Programa Geral de Treina mento, relativo ao Ano III, 19641965; III - Programa Geral de Treinamento do Ano III - Anexos. Análise da Previsão Orçamentária. Anexo Documento $\mathrm{n}^{\circ} 1$, inclusive Anexos 2, 3 e 4 que tra. tam do Programa dos Operadores de Subestação.

La Corriente Internacional de Capital a Largo Plazo y de Domaciones Oficiales - Este é o terceiro de uma nova série de estudos anuais sôbre a corrente internacional de capital a largo prazo e de doaçøes oficiais. Nêle se examina a corrente de fundos procedentes dos países desenvolvidos, e até a co:rente de fundos dos paises insuficientemente desenvolvidos, e a ajuda econômico-internacional dos países com planificação econômica centralizada durante os anos de 1960 a 1962 e, até onde permitem os dados do ano de 1963. Este informe foi preparado em cumprimento a várias resoluçốes do Conselho Econômico Social.

Uma versão preliminar dêste informe (documento A-5.546), baseada em dados incompletos, foi apresentada à Assembléia Geral em seu décimo oitavo periodo de sessões.

Palavras iniciais constam de um Preâmbulo em que são explicados os autênticos objetivos desta publicação, escrita em espanhol, conforme vem, agora, para a América Latina, a majoria das publicações editadas pelas Nações Unidas. A presente trás a rubrica do Departamento de Assuntos Econômicos e Sociais das Nações Unidas.

O Cultivador - Este é um órgão oficial, informativo, agricola e cultural do Colégio Agrícola de Santa Teresa, que ensina e orienta o lavrador em suas atividades. No exemplar do Ano XVIII - Nes 213-14, de março-abril de 1964 , editado em São João de Petrópolis, o artigo de fundo é dedicado à Companheira do Lavrador, exaltando-lhe seu valor anônimo, cujo mérito reside no árduo e irrealçá- vel labor caseiro, cotidiano $e$ intimo, que ela desempenha sempre com incansável ânimo, carinho e abnegação, sem ser vista nem citada, como se não estivesse, dessa forma, contribuindo para o engrandecimento da economia nacional. E' ela figura indispensável ao lado do agricultor, sem a qual, o seu lar seria desorganizado, ficariam ao léu seus filhos, sua vida, enfim, se tumultuaria, e ao impacto dessas consequiências, a produção nacional sofreria, provocan$\mathrm{d}_{0}$ defasagem no comércio e diminuição de lucros na balança internacional. Por isso, êsse jornal, exclusivo do agricultor, resolveu exaltar sua companheira, neste editorial, lembrando que é a espôsa do lavrador o seu sustentáculo, a sua amiga e sua inspiraçáo, por ser mulher a pessoa que cultiva com o peculiar carinho dos corações feniminos, o confôrto no lar.

Os demais artigos debatem problemas especificos de gado e lavoura, em geral, focalizando também, alguns conselhos e máximas literárias comuns.

O exemplar $n^{\text {os }} 215-16$ noticia a "Próxima Semana do Lavrador", que deverá ocorrer entre 26 a 31 de julho dêste ano.

Esta publicação é editada no Est. do Espírito Santo.

Diário Oficial do Estado de Sergipe - Este jornal é o órgão informativo oficial dos atos do Govêrno dessa unidade da Federação dos Estados Brasileiros. Nêle se contém o noticiário do Gabinete do Gove-nador, além dos demais atos do Poder Executivo local, bem como, leis, decretos, editais e demais decisões exaradas por aquela autoridade. Possui, também, infor maçóes e noticiário dos outros órgáos componentes daquele Poder. Integra, ainda, o mesmo a parte pertencente ao Diáric da Axsem. bléia Legislativa de Sergipe.

Economia y Ciencias Sociales - Em nosso poder, presentemente, os $n^{\text {es }} 1$ y 2 , del Año VI - segunda 
epoca - enero-junio de 1964, da Revista da Faculdade de Economia da Universidade Central de Venezuela. $\mathrm{Na}$ grande variedade dos artigos que esta revista abrange, se entrosam temas correlatos aos seus objetivos, encontrando-se nela, ainda, um artigo sôbre Semânítica, inţtulado "Contribucion al estudio de la fonemica, idioma Guajibro", de autoria de Eteban Emilio Monsonyl; há outro cujo autor é José Gallego Diaz, Docente da Universidade Central de Venezuela, a respeito de economia, cujo título é "Sobre un principio de minimaccion en Economia Politica", que é um prefácio da tese do autor, apresentada à Universidade Central de Madrid, em que o mesmo resumiu suas investigações, neste ensaio, no qual expõe suas teorias sôbre o principio filosófico do mínimo de trabalho, ou seja a minima ação aplicada à Economia Politica. Seu autor faleceu às vésperas de ser editada esta publicação, tendo revisto as provas de imprensa de seu artigo, dois dias antes de sua morte.

A Educação Cívica e Politica da Mulher - Publicação das Nações Unidas, trata de direitos e deveres. tanto civicos como políticos surgidos com a participação da mulher na vida pública, e oferece sugestões para fomentar a participação dela nesse âmbito. Cita alguns exemplos do procedimento utilizado para a educação civica e politica da mulher, mencionando ainda, o sistema adotado pelas $\mathrm{Na}$ ções Unidas.

Escola de Minas - Esta é uma revista publicada por alunos daquela Escola, e reconhecida pelo Diretório Acadêmico da Escola de Minas Ouro Prêto, fundada em 1936. Trata, de modo geral, de tudo quanto se relacione com Geologia - Engenharia de minas - Engenharia civil - Engenharia metalúrgica e matérias afins. O sumário do $n^{\circ} 4$ - volume XXIII, de 12 de outubro de 1964, nos ofere- ce assuntos como: "Introdução ao estudo das madeiras", de Moacyr do Amaral Lisboa; "Leis Básicas de Hidráulica fluvial", cujo autor é Célio Mendes; "Gruta da Igrejinha", escrito por Fernando Saraiva Salgado, aluno do $6^{\circ}$ ano da referida Escola, e Presidente da SEE durante o período de 1963-64, tendo sido apontada a referida Igreja para tema dêsse artigo, em virtude de ter sido aquêle local escolhido para pesquisas metalúrgicas na gruta ali existente, pelos alunos daquela Escola. O volume XXIV $\mathrm{n}^{\circ}$ 1, de março de 1965, apresenta a continuação do artigo "Introdução eo Estudo das Madeiras". Ainda, de autoria de José de Carvalho Lopes; o estudo denominado "Breve noticias sôbre a Escola de Minas de Ouro Prêto", em que, a respeito de sua origem e desenvolvimento, ficamos sabendo que ela foi criada pelo Decreto $\mathrm{n}^{\circ} 6.026$, de 6-11-875, expedido pelo Govêrno Imperial, tendo iniciado suas atividades em 12 de outubro do ano de 1876. Foi a primeira escola dêsse tipo na América do Sul.

Estudo Econômico Mundial Relativo a 1963 - Apresentada pelo Departamento de Assuntos Econômicos e Sociais a parte II, estuda a recente evolução, e trata da produção e do equilibrio interno e das tendências reinantes nos paises industrializados e nos paises de exportação de matérias-primas, porém, não exportador de produtos manufaturados. Trata ainda, de paises com economia de planificação cent:alizada na agropecuária. Estuda também, a evolução na indústria, inversões de capital, comércio interno e comércio com o exterior, e apresenta planos para 1964.

Guanabara Industrial - Orgão oficial do Centro Industrial do Rio de Janeiro e da Federação das Indústrias do Estado da Guanabara. Do Ano III desta publicação, temos em mãos, os $\mathrm{n}^{\text {ss }} 27$, de abril dêste ano; 28 , refe:ente a maio e 29 , re- 
ferente a junho também do corrente ano, editados no Estado da Guanabara, Brasil. Em seus editoriais esta revista debate sempre algum momentâneo problema ligado à indústria nacional ou internacional, ou mesmo de caráter estritamente local. No exemplar que se refere a maio, desde sua capa, que a revista focaliza o fato de que, nesse mês, se comemora em todo - pais o "Dia da Indústria", a 25 de maio, data aniversária do nascimento de Roberto Simonsen, - saudoso lider da classe e um dos pioneiros da nova politica social implantada no Brasil, a partir de 1945. Tal comemoração decorre de decreto oficial $n^{2} 43.769-58$, pelo que nos informa o mesmo editorial.

A revista de junho trata das solenidades da mencionada Semana, as quais foram iniciadas pelo Dr. José Ignacio Caldeira Versiani, Presidente da FIEGA - Federação da Indústria do Estado da Guanabara. Sua capa apresenta uma visão ampla do recém-inaugurado Viaduto dos Marinheiros, uma das mais belas obras públicas ùltimamente construidas no Estado da Guanabara, grandioso empreendimento para o tráfego rodoviário local; cumprindo o objetivo a que se destina, encurta de muitos minutos a distância ent'e a zona norte e o centro da cidade guanabarina, sendo um dos muitos benefícios com que o povo carioca está vendo retribuido o seu esfôrço $\mathrm{n}_{\mathrm{O}}$ sentido de melhorar urbanisticamente sua cidade, a fim de torná-la uma metrópole mais confortável ao convivio, neste ano que é destinado a seu $4^{\circ}$ centenário.

IDORT - Revista de organização e produtividade do Instituto de Organização Racional do Trabalho, filiado ao CIOS, órgão internacional. O exemplar de $\mathrm{n}^{\mathrm{is}} 395-6$, do Ano XXXIII - relativa aos meses de novembro-dezembro de 1964 . editado em São Paulo, Brasil, nos informa que foi eleito o nôvo Presidente do IDORT, que é o Senhor
Manoel dos Reis Araújo, em eleição que se realizou a 28 de abril do ano findo, no auditório do Instituto de Organização Nacional do Trabalho, para preencher vaga aberta com o falecimento do Presidente anterior. O colaborador costumeiro desta publicação, Senhor Pedro Ferraz do Amaral, exSecretário Executivo dêste Instituto, apresenta o artigo "40 Anos de Organização Cientifica na França". A respeito de cursos de administração, aparece no presente exemplar, um levantamento feito com dados obtidos por solicitaçăo, em várias escolas dessa natureza, sob o título "Pesquisas sôbre entidades de Ensino de Administração", sendo conclusão de número anterior. Há ainda neste mesmo número objetiva e minuciosa apreciaçáo feita por Manoel de Castro Vilas Boas, em tôrno da nossa atual agro-indústria cafeeira, suas falhas e soluções, intitulada pela seguinte indagação: O Brasil voltará a queimar café? $\mathrm{Em}$ anexo a revista apresenta o Indice do Trigésimo terceiro volume do IDORT - Revista de Organização e Produtividade, relativo a 1964.

Informações do Utuguai - Este é um boletim editado pelo SEPRO Serviço de Propaganda e Expansăo da Embaixada do Brasil no Uruguai, divulgador de noticiário de fatos e atos de grande realce do Govêrno uruguaio, e outrossim, do Govêrno brasileiro. Regista também, visitas oficiais de autoridades dos dois paises. Oferece, igualmente, noticias comerciais, de pecuária, câmbio, importação e exportação de ambos os paises, inclusive previsão do tempo naquela capital sul-americana, fornecida pelo Observatório Antares, da cidade de Montevidéu, previstas para os próximos dias do mês seguinte àquele ao qual pertence $\circ$ boletim em causa. Os que temos em nossa redaçăo, agora, são os de $n^{\circ /} 4,5$ e 6 , relativos aos meses de abril, de maio e de junho do corrente ano. pertencentes ao Ano IV da mesma 
publicação, editados em Montevidèu, no U̇ruguai.

O boletim de $n^{*} 6$, dentre ou tras notícias, presta informações proporcionadas pelo Departamento de Estatistica do Banco da Republica Oriental do Uruguai, em que o mesmo divulga o total das exportações uruguaias no primeiro trimestre dêste ano. A exportação de carnes e derivados, nessa época, ultrapassou o resultado constatado em 1964.

Informacion Juridica - Esta publicaçáo, cuja orientação é dirigida por Arturo Gallardo Rueda, apresenta sempre algum documento juridico, e, neste exemplar de $n^{\circ s}$ 260-1, de enero-febrero de 1965, editado em Madrid, na Espanha, se encontra o Código de Procedimento Civil de Chile - Tomo I; Libro Primero e Libro II. O Libro I trata das "Disposiciones Comunes a Todo Procedimento", apresentado com todos os seus capitulos que têm aqui a designação de Titulos. O Libro II trata "Del Juicio Ordinario", e se acha integrado por todos os seus Titulos. ........

Jurispeudência e Doutrina - Publicacação de propriedade da Editôra Juridica Ltda. O volume $\mathrm{n}^{\circ} 54$, de abril-maio-junho de 1964, editado na cidade de Fortaleza, capital do Estado brasileiro do Ceará, registra apresentação do resumo de sua matéria, dois interessantes artigos, enquadrados na parte desta publicaçăo que é destinada à Doutrina. São êles: de autoria do Dr. Edésio Grmes de Matos, co. laborador da sucursal do Jornal do Brasil, em Brasilial, os artigos: "Do Assento ao Prejulgado; Símula é revoltução no Supremo". $\mathrm{O}$ outro, é intitulado "O Latim no Ensino Juridico", que esta revista divulga, em virtude da atualidade do assunto; trata do memorial que a Associação de Estudos Clássicos e Sociedade de Estudos Filológicos, de Sáo Paulo, dirigiu à douta Congregação da Faculdade de Direito da Universidade daquêle Es- tado, sôbre o Latim no ensino jurídico.

A parte de jurisprudência anota jurisprudência civel e penal, e fornece ainda um ementário do S.T.F.

Termina o exemplar com um indice geral de tôda matéria nêle contida.

O $\mathrm{n}^{\circ} 55$, de julho-agôsto-setembro de 1964, também de Fortaleza, no Ceará, nos revela ser esta, uma publicação autorizada pelo Tribunal de Justiça daquele Estado, inclusive o Tribunal Regional do Trabalho sediado em Fortaleza, mais o Tribunal de Contas do mesmo Estado brasileiro, e ainda a Orilem dos Advogados - Seção do Ceará, que coleta vasta bagagem extraida dos órgãos judiciários localizados nesse Estado.

Contém o presente exemplar, artigos que são: "Atos Judiciais em dias úteis", de autoria do Dr. Luís Pereira de Melo, Desembargador do Tribunal de Justiça de Sergipe e Professor da Faculdade de Direito; "A legitima defesa na $\mathrm{Bi}$ blia", de autoria do Juiz de Direito Valdetaro Pinheiro Mota; além de um estudo sôbre um $\mathrm{Pa}$ recer, intitulado - Interpretação do inciso IV, do artigo 124 da Constituição Federal. $\mathrm{O}$ veto dos Tribunais de Justiça às promoções de juízes por antigüidade, só se aplica nas promoções ao cargo de Desembargador.

$\mathrm{Na}$ seção de Legislação dêste exemplar, vem transcrita a Lei $n^{\circ} 4.357$ de 16-7-64, que indica todo o critério de lançamento das Obrigações do Tesouro Nacional, e o Decreto $n^{\circ}$ 53.984, de 25-6-64. Há ainda um Indice Geral da referida publicação.

Jornal da Aspep - Um órgão a serviço do funcionalismo. $O \mathrm{n} * 24$ referente a abril de 1965, do Ano $\mathrm{V}$, dêste jornal editado na cidade de Joăo Pessoa, no Estado brasileiro da Paraiba, focaliza o transcurso do centenário de nascimento do inclito paraibano Epitácio da 
Silva Pessoa, nascido no municipio de Umbuzeiro, naquele Estado. Foi - mesmo, Presidente da República dos Estados Unidos do Brasil, durante o periodo de 1918 a 1922 . Era homem de invejável cultura, jurista emérito e de renomado talento, tendo se distinguido no govêrno pela dedicação que tributou ao Nordeste do pais, o qual the deve a mais carinhosa assistência material e moral, pelas iniciativas de valor que teve. Destacaram-se dentre essas, as obras contra as sêcas, então terrível flagelo brasileiro, incluindo-se nelas, a nacionalização da pesca, o socorro à lavoura cafeeira bandeirante outrossim, ao crédito, propiciando, na época, um clima de garantia à ordem pública, realizando, assim, um Govêrno legalista e de paz. Estando êle na Presidência por ocasião do centenário da proclamação de nossa independência, em 1922, baixou lei revogando o banimento da familia imperial do Brasil e o conseqüente repatriamento dos restos mortais dos ex-imperadores D. Pedro II e D. Teresa Cristina, prestando a êsses, homenagens de Chefe de Estado, e traçando festlvo programa de comemorações, até mesmo internacional, para saudar - glorioso século daquela proclamação. Viajaram, então, os dois corpos dos antigos Imperadores, em couraçado brasileiro, especialmente enviado a Lisboa para êsse fim. Era uma autêntica reivindicação de todo o povo brasileiro àqueles que tanto o haviam amado.

Aparece ainda, no mesmo jornal, sob o título "Nostalgia de Cajueiro", um comentário a respeito da môsca branca que dizima os cajueiros, e num verdadeiro libelo ao Poder Público, cita seu articulista - Antônio Freire - outras pragas semelhantes, tais como: a da lagarta nos algodoais, a formiga e o gafanhoto que destroem as plantações; lamenta também, que os departamentos de defesa animal e vegetal que existem distribuidos pelo Estado, não os combatam, por se encontrarem sempre desaparelhados para cumprirem seus encargos.

Journal Official de la République Française - Apresenta a Lei n' 64-1265 de 22-12-64, que aprova o Relatório sôbre as principais opçôes que orientam a preparação do $5^{\circ}$ Plano do Govêrno Francês. N' 299 96 année - 23-12-64. Rue Desaix $\mathrm{n}^{\circ} 26, \mathrm{~Pa}$-is $-15 \mathrm{e}$.

Livros de Portugal - O presente boletim $\mathrm{n}^{\circ} 76$, de abril de 1965, editado em Lisboa, comenta em seu editorial a atuação que tem tido o Grêmio Nacional dos Editores e Livreiros, além de enaltecê-lo, dizendo que não tem êle procurado auferir lucros quando se trata do Livro e de Cultura Portuguêses. P-osseguindo, refere-se à defesa dos interêsses de seus agremiados, de forma que não colida com a atividade de divulgação cultural que sempre achou por bem, não desprezar. Fala-nos ainda, êste editorial do "Prêmio Golfinho", criado neste ano, pela Associação Brasileira do Livro, inspirado no cetáceo que compõe, como um dos elementos integrantes, o emblema da cidade do Rio de Janeiro, com que foi agraciado êsse Grêmio, única instituição estrangeira a recebê-lo.

Mais adiante, aparece uma reportagem concedida pelo Dr. Borges de Castro, Presidente do supracitado Grêmio, desde 1957, ao Jornal "A Tribuna", em 2 de março dêste ano, sôbre os problemas ligados ao livro, genèricamente, e falou, também, a respeito do caso especifico da exportação de livros portuguêses para o Brasil.

A capa dêste folheto mostra a fotografia de Antônio Feliciano de Castilho, na seção intitulada ECOS. Foi o poeta romântico do século passado, crítico, prosador, e tradutor de Ovídio e de Molière. O Cego desde os 6 anos de idade, escreveu, entretanto, até além dos 60 , pouco antes de mo:rer, deixan- 
do vasta bagagem literária. Publica êsse folheto, completa biografia sua, em virtude de ocorrer neste ano, o nonagésimo aniversário de seu falecimento.

$O$ boletion de $\mathrm{n}^{\circ} 77$, referente a maio dêste ano, nos fala da XXXV Feira do Livro realizada em Lisboa a 15 de maio, à qual compareceu sua Excelência, o Chefe de Estado da Nação Portuguêsa, Sr. Almirante Américo Thomaz. Nessa feira, houve um dia dedicado ao liv:o brasileiro, comparecendo, nesse dia, o Sr. Embaixador do Brasil. acompanhado pelo Dr. Odylo Costa e, pelo Cônsul-Geral dêsse pais.

Landmarys in International Cooperation -- Livro editado pela Organização das Nações Unidas, que explica o prog-esso geral, social e econômico, e, igualmente, quais têm sido os beneficios da ciência para o bem dos homens. Desenvolve o assunto, entrando nos campos de Saúde, da Educação e das Comunicações. Explica, finalmente, a Lei Internacional, e fala sôbre o Direito dos Homens e Assistência às Crianças.

Manual de Encuestas sôbre Hogares - Publicação em espanhol, pertencente à série $\mathrm{F}-\mathrm{N}^{\bullet} 10$, de 1964, edição das Nações Unidas, da Oficina de Estadistica de las Naciones Unidas do Departamento de Assuntos Econômicos e Sociais, versando sôbre Estudos e Métodos, num verdadeiro manual de informações a respeito de lares e residências. Diz em sua apresentação que êste Manual é um trabalho conjunto das Nações Unidas em colaboração com a OIT, a PAO e a OMS, e que é também, um guia prático para investigações de niveis de vida. Divide-se êste volume em 3 partes, sendo que a última delas consubstancia um Indice Analítico e Alfabético de Assuntos dessa publicação.

Mensário Estatistico - Recebemos dois exemplares dessa publicação, e con- forme se pode depreender de seu próprio título, estas revistas apresentam gráfico e quadros concernentes a finanças públicas; moeda e câmbio; movimento báncário; comércio com o exterior; comércio de cabotagem, etc. Os números em nosso poder são: 165 , de março de 1965 e 166, de abril do mesmo ano, editados no Ministério da $\mathrm{Fa}$ zenda do Brasil; No primeiro dèles se encontra publicada a Portaria $n^{2} 24$ de 21-12-64, expedida pelo Diretor do Serviço de Estatística Econômica e Financeira, que estuda novos critérios para a revisão periódica da Nomenclatura Brasileira de Mercadorias, com o objetivo de mantê-la sempre atualizada. Este trabalho é feito, em face dos levantamentos elaborados pela $\mathrm{Co}$ missão Permanente de Classificação da NBM, sigla que traduz a citada nomenclatura, a qual funciona junto a êste Serviço, a que é incumbida de indicar as minimas e indispensáveis alterações a que a referida Nomenclatura estiver sujeita, ocasionalmente.

Ministerio de Hacienda de Mardrid Apéndice a la Información estatistica del Ministerio, em 1962. A Secretaria Geral de Técnica do Ministério de Fazenda da Espanha apresenta os orçamentos iniciais para 1962, dos Organismos Autônomos de Administração do Estado - M'CMLXIII - Resumo Geral de Entradas e Despesas Espanha - Madrid.

Outra separata revela o "Texto do Discurso" pronunciado pelo Exmo. Sr. Ministro da Fazenda, Don Mariano, Navarro Rubio, na sessão plenária das Côrtes de Espanha, no dia 27 de dezembro de 1963.

New Sources of Energy - Sources Nouvelles d'Energie. Atos oficiais da Conferência em Roma, realizada no periodo de 21 a 31 de agôsto de 1961. O Volume 5 focaliza a utilização da energia solar para fins de aquecimento, dan- 
do informações sôbre experiências em vários paises.

O Volume 6 trata de energia solar, de ventos e ainda, de energia geotermal, e sua utilização em vários paises.

Noticias de Portugal - Este é um boletim do Secretariado Naciunal da Informação, através do qual nos chegam as mais importantes noticias do que ocorre naquele pais europeu. Pelos boletins de ns. 935 ao de $\mathrm{n}^{\circ} 946$ que datam de 3 de abril do Ano XVIII até 19 de junho - Ano XIX desta publicação, editados semanalmente, em Lisboa, verifica-se que o movimento cultural e politico, administrativo $e$ internacional, é todo ali registrado e documentado com fo. tografias que fixam o movimento em que o fato se deu. Alguns boletins dêsse periodo nos comunicam que a partir de abril do ano em curso, se *ealizará a II Feira Nacional da Agricultura, em Santarém, Portugal, e o Brasil se fará representar, explicando que já existe para ser localizada na mesma, um projeto de um pavilhão construido por $\mathrm{am}$ a:quiteto brasileiro, em que é prevista una área coberta de quinhentos metros quadrados, onde serăo expostos tratores, maquinaria agricola e outros produtos da indústria brasileira. Outro, nos informa que o Governador Carlos Lacerda declarou, quando de sua visita a Lisboa, que na cidade de São Sebastiăo do Rio de Janeiro será instalado o Museu da Imagem e do Som numa homenagem às comemorações do ano do IV Centenário dessa cidade.

$O$ de $\mathrm{n}^{\circ}$ 942, mostra-nos um flagrante do Presidente da Academia Brasileira de Letras. escritor Austregesilo de Athayde, recebendo a Grấ Cruz de Christo, quando visitou aquêle país, a convite da Academia das Ciências, a 13 de maio dêste ano.

O bo'etim de 15 de maio comunica a exposição que Portugal instalará no Estado da Guanabara, intituiada "Portugal de Hoje", em homenagem ao $4^{\circ}$ Centenário da Cidade de São Sebastiáo do Rio de Janeiro, a qual ficará localizada na Avenida Chile.

Ainda o de 12 de junho fixa instante da visita a esta terra, do Ministro Português dos Negócios Estrangeiros, a fim de representar seu pais nas cerimonnias comemorativas do $4^{\circ}$ Centenário da já citada cidade, quando êsse ministro fazia entrega de 2 exemplares de um livro editado em Portugal, a respeito do Rio de Janeiro, ao Marechal Presidente do Brasil Hum. berto Castelo Branco.

Noticiário das Nações Unidas - Éste boletim é enviado gratuitamente a bibliotecas, redações de jornais e de revistas, estaçỏes de rádio e televisão, associaçốes, clubes $e$ a particulares. Temos o n' 2 relativo ao Ano XIV do periodo de março/Abril do corrente ano, em edição brasileira e são assuntos dêste boletim: "A Economia Latino-americana $\mathrm{em}$ pauta"; "Melhorando a Saúde Mundial"; "U.I.T.: Cem anos de cooperação internacional". Explicando o que é a UIT, seu noticiário mais amplo nos informa que, ao lado da ONU existem entidades especializadas que são verdadeiras organizaçốes internacionais, e a União Internacional de Telecomunicações, é a mais antiga delas, pois completa 100 anos em 1965; foi ela instituida por um convênio realizado em Paris, por 16 nações, a 17 de maio de 1865 . cm que foi adotado o emprêgo de tarifas internacionais uniformes para quase tôda a Europa, tendo o franco-ouro francês como moedapadrão. Posterio:mente, outras foram também rẹalizadas, vindo até nossos dias de era espacial.

No boletim do Ano XIV $\mathrm{N}^{\circ} 3$ - referente a maio-junho do corrente ano, proveniente da ONU, em New York, nos Estados Únidos da América do Norte, 
aparece como artigo de fundo, uma série de informes sôbre assinatura da Carta da ONU, sob o título "Uma data histórica: 26 de junho de 1945". Este artigo nos diz que há 20 anos, na cidade de São Francisco da Califórnia, reuniramse no Teatro Municipal daquela cidade, 21 nações amantes da paz, que solenemente apuseram as respectivas assinaturas na Carta das Nações Unidas, assumindo o sagrado compromisso de assegurar a paz e a segurança internacionais, inclusive $\mathrm{o}$ respeito às liberdades fundamentais e aos direitos humanos. Formula, ainda, melhores condições de vida para todos numa liberdade mais ampla. Esse conclave durou de 25 de abril até 26 de junho daquêle ano. Ilustra tal artigo, uma foto da ocasião em que o Embaixador Pedro Leão Veloso, representante do Brasil àquela conferência, apunha sua assinatura, pelo pais que representava, no momento histórico das assinaturas da Carta das Nações.

\section{Noticeiro Bibliotecario Interamericano} - Publicação trimestral editada pela Biblioteca Colón. O $\mathrm{n}^{\circ} 37$. de julho-setembro de 1964, dêste boletim, editado em espanhol, trata de todos os assuntos que se identificam com o tema que seu nome indica. Contém o presente, 6 itens, nos quais se enquadram tôdas as seções do mesmo, obedecendo aos seguintes títulos: Relações Internacionais; Associações e Conferênrias; Peparação Profissional; $\mathrm{Bi}$ bliotecários; Bibliotecas; Literatura Profissional; estas seções ainda se subdividem em outras. Na $1^{*}$ dentre essas citadas, aparece o resumo de um artigo do Sr. Edson Nery da Fonseca, Bibliotecário da Câmara dos Deputados do Brasil, em que o autor adverte em certo trecho desta análise, ser precária a alfabetização e a educação fundamentais, apoiadas sòmente nas salas de aula, sem inculcar no recente alfabetizado o gôsto e o costume de ler. Alega que isto favorece o crescimento do analfa- betismo, e que a condição de limitar o estudo do pessoal do interior do país ao local das salas de aula, não se ampliando o mesmo pelas consultas às bibliotecas, torna precário o ensino, além de tirar - gôsto pela leitura.

Fala êsse mesmo boletim, de uma Semana do Bibliotecário a se realizar na Colômbia, de 20 a 25 de abril de 1965. Mais adiante, há uma página dedicada à Associações e Conferências, onde noticiam a realização do V Congresso Brasileiro de Biblioteconomia e Documentação, que deverá efetuar-se a 4 de outubro do corrente ano, na Universidade de Minas Gerais, na cidade de Belo Horizonte, no Brasil.

Qdontopediatria -- III Congresso de Odontopediatria - Boletim informativo da A.B.E.N.O., informando sôbre a I Reunião Nacional de Professôres de Odontopediatria. Este congresso deverá realizar-se de $1^{\circ}$ a 5 de setembro vindouro, no Estado de S. Paulo, no Brasil. Dentre as providências que estão sendo tomadas, presentemente, a comissão o"ganizadora central, já expediu ofícios a diversos governadores estaduais brasileiros, solicitando o abono de ponto, nesse periodo, para os profissionais e demais interessados que queiram comparecer àquele conclave. Informa, ainda o mesmo boletim, que os governadores carioca e paulista já autorizaram tal concessão, esperando, apenas que cada funcionário assim se manifeste.

Mais adiante, esclarece que a 30 de agôsto do corrente ano ocorrerá, verdadeiramente o primeiro encontro entre os professôres, ficando a abertura oficial do referido congresso para $1^{\circ}$ do mês seguinte, e que o mesmo, terá a supervisão da A.B.E.N.O.

Os trabalhos cientificos deverão ser enviados, no máximo, até 30 de julho, a fim de que possam ser julgados e programados, para a Secretaria da C.O.C., localizada 
à rua Humaitá, 389 - caixa postal 252, no Estado de São Paulo.

Paraná Econômico - Orgão defensor dos interêsses econômicos do Estado. Traz sempre em suas capas, uma fotografia de um local qualquer dêsse Estado. Com suas seções costumeiras "Nossa Opinião", "Paraná em foco" e "Atividades do SESC Paranaense", e outras mais, esta publicação divulga em suas páginas o que de mais importante ocorre que possa fazer parte do noticiário estadual, nesse periodo. E' publicado pela Federação do Comércio do Estado do Paraná, em colaboração com a $\mathrm{Fe}$ deração das Indústrias do mesmo Estado, mais o Serviço Social do Comércio e o Serviço Nacional de Aprendizagem Come-cial. Temos em mãos o $\mathrm{n}^{\circ} 145$, de abril dêste ano, e o de $\mathrm{n}^{\circ \mathrm{s}}$ 146-7, referente a maio-junho de 1965 também, correspondendo ambos os volumes ao Ano XIII da publicação em foco.

Planning for Economic Development -"Studies of National Planning Experience". Parte I - Empreendimentos particulares e Economia Mista no Brasil, Colômbia, India, Japão, Holanda, Paquistão e República Árabe. Parte II, composta de dois volumes, do qual o primeiro estuda a Economia concentrada da Hungria, Rússia e Tchecoslováquia.

Prefeitura Municipal de Blumenau Lei orçamentária do Municipio de Blumenau. Publicação avulsa da Coleção de Leis do Ano de 1964, promulgadas pelo Prefeito Hercilio Deeke, do Municipio catarinense de Blumenau, no sul do Brasil. A lei, de $n^{\bullet} 1.300$ de $11-12-64$, orça a Receita e fixa a Despesa para o exercicio de 1965, daquêle municipio, apresenta os respectivos quadros demonstrativos, segundo os vá-ios critérios de subdivisáo orçamentária.

Revista de Administração Municipal O presente exemplar, de $n^{\circ} 69$, é do Ano XII, referente ao bimestre março-abril de 1965 , editado no Es- tado da Guanabara, no Brasil. Seu editorial trata de "Reforma Municipal em São Paulo". Apresenta o mesmo volume assuntos sempre atualizados e enquadrados nas respectivas sessões desta revista, que são, habitualmente, os seguintes: Planejamento e Urbanismo; Administração financeira; Assuntos Diversos; Pequenas noticias; Legislação \& Jurisprudência, e outra, ainda, que é Publicações em Revista. Nesta última seção mencionada, aparece aqui, o boletim do Centro de Pesquisas Administrativas da EBAP, sigla que traduz a Escola Basileira de Addministração Pública, pertencente à Fundação Getúlio Vargas. Finaliza esta publicação a seção de "Publicações Recebidas pela Biblioteca do I.B.A.M."

Revista de Administracion Publica Editada pelo I.A.S.P. da Secretaria de Estado de Hacienda de la Republica Argentina. Possui tal publicação, uma separação de sua matéria, por seções, e êste volume foi todo dedicado ao III Conaresso Nacional de Administracão Pública, realizado de 16 a 21 de novembro de 1964, aparecendo, no final do volume, dados biográficos dos participantes daquêle Seminário. Encontra-se, também. a seçăo intitulada "Revista das Revistas", na qual são estudadas as publicações que a redação recebe. Em nossa redação temos, presentemente: N*14-5 - Año IV - juliosetiembre y octubre-diciembre de 1964 - Buenos Aires - Argentina.

Rcvista de Administracion Pública "Publicada semestralmente por la Escuela de Administracion Publica, Del Colegio de Ciencias Sociales, de la Unive"sided de Puerto Rico". No exemplar de $n^{\circ} 2$ - volume I - dezembro de 1964, entre alguns de seus artigos, aparece um a respeito de nosso pais, que se intitula El Regimen de Gobierno Estatal en Brasil, sus desarrollos recientes y) su efecto sobre el sistema tederal, de autoria de George W. Benis, Professor visitante, na $\mathrm{Fa}$ - 
culdad de Ciencias Sociales, Escuela de Administración Pública, de la Universidad de Puerto Rico.

Out o importante artigo que, por seu interêsse achamos oportuno consignar, é: La Democracia y el Servicio Publico, cujo autor é E. de la Rosa. A revista apresenta ainda uma seção em que livros são comentados, e outra de sinteses informativas, que finalizam a publicação.

Revista Brasileira de Estudos Politicos - Fundada em 1956. Esta revista confirma seu próprio nome apresentando estudos que envolvem profundos e madu"os conceitos sôbre politica nacional, em seus mais variados setores. Seus colaboradores são, portanto, pessoas dedicadas ao trato das coisas públicas e atentos observadores dos problemas brasileiros $\mathrm{e}$ de suas possiveis e plausiveis soluções. Alguns dêsses nomes aparecem no $n^{\circ} 18$, de janeiro de 1965 , dessa publicação editada na cidade de Belo Horizonte, no Estado de Minas Gerais, com criticas de livros sôbre Politica, Socialismo, Administ"ação Pública, História, Direito e outros assuntos mais. Possui os mais diversos artigos, dos quais alguns são: Análise de Segurança Nacional, por Augusto Estellita Lins; "Habitação - Familia - Democracia", cuja autoria é de André Franco Montoro, ex-ocupante da pasta $\mathrm{d}_{\mathrm{o}}$ Ministério do Trabalho. Ass'nado por Beatriz $M$. de Souza Wahrlich, Direto a da Escola Brasileira de Administracão Pública do Rio de Taneiro (EBAP).

A publicação termina com o registro das publicações recebidas, e livros recebidos pela referida Universidade.

Rcvista de Ciencias Sociales - Esta revista é publicada t-imestralmente em março, junho setembro e dezembro, pelo Colégio de Ciências Sociais da Un'versidade de Pôrto Rico, em Rio Piedras. Seus assuntos do $\mathrm{n}^{2} 4$ - volume VIII Diciembre, 1964, focalizam tudo quanto se relaciona com as cha- madas ciências sociais. Neste exemplar, sob a clássica epigrafe latina In Memorian, o Diretor da Revista reverencia a figura de Carlos Hernández (1919-1964), que foi mem. bro da Junta Diretoria desta revista, e professor da cadeira de Psicologia da Faculdade de Colegio de Ciencias Sociais de Pôrto Rico, enaltecendo-lhe as virtudes de patriotismo, honestidade e dedicação de verdadeiro pedagogo que foi. Existem ainda nesta publicação, resenhas de livros, registro de liv"os receb:dos, finalizando a mesma, com $\mathrm{u}_{\mathrm{m}}$ Indice Geral do volume VIII, $\mathrm{n}^{\circ \mathrm{s}} 1,2,3$ e 4 .

Revista do Conselho Nacional de Economia - Orgão oficial do C.N.E. $O$ edital do $n^{\circ} 1$ do Ano XIV, referente a janeiro-abril de 1965 , cuida da criação do Conselho Monetário Nacional e do Banco Central da República do Brasil, organismos que se destinam a ampliar as atribuições da antiga SUMOC e de seu Conselho. Há na mesma, uma seleção de Resoluções do Conselho do citado órgão, dentre as quais, a de $n^{\circ} 6-64$, expedida pelo Presidente do mesmo, Humberto Bastos, a 7 de dezembro acolhe parecer do Conselheiro Glycon de Paiva, relator do processo estudado pelo Plenário do Conselho, em que êste aprovou os coeficientes de correção monetária para atualização das obrigações do Tesouro Nacional, e também, dos débitos fiscais e das contribuições devidas às entidades de Previdência Social. De acôrdo com o que estabelece o artigo $7^{\circ} \S 1^{\circ}$ da Lei $n^{\circ} 4.357$, de 16-7-64, é o Conselho incumbido de fixa- em cada trimestre, os coeficientes de atualização da moeda, que deverão vigorar no trimestre civil imediato. Tais indices se baseiam na média móvel trimestral dos valôres de preços por atacado, As outras Resoluções, de $n^{\text {'s }}$ 1-65 e 2-65, fixam, também, coeficientes de correção monetária, respectivamente, para o capital de giro das emprêsas, e para reavaliação 
dos ativos imobilizados de firmas ou sociedades.

Esta revista apresenta, a seguir, uma série de conferências versando tôdas sôbre economia e assuntos que com ela se relacionam. Estudos e Pesquisas é outra seção, a qual apresenta, neste número, dois estudos, sendo um sôb:e "Amazônia, primeira grande experiência brasilei:a de planejamento regional", que traz a assinatura de Armando Mendes.

Há nêle mais o seguinte: Noticiário e Documentação, que termina com a publicação do Indice alfabét' $c_{0}$ da Revista do C.N.E., em 1964.

Revista Danesa - O n 14 de 1964 , desta revista nos revela que, em cada ano, as organizações econômicas da Dinamarca nomeiam um comitê especial encarregado de revisar os projetos para as feiras e exposições que se realizarão no pais durante o ano. Após isso, é publicado um resumo dessas feiras e exposições que são as consideradas de grande categoria. O referido resumo preparado para o ano em curso, apresenta uma gravura do interior da seção denominada "Bella - Centret de Copenhague", que deve-á ficar localizada na parte de stands compactos, no Nôvo Salão de Exposições, que será o maior da Escandinávia.

Possui o presente exemplar capas duplas, sendo ambas ilustradas, graciosamente, com os diversos produtos que serão apresentados na respectiva Feira, tais como calçados, roupas, móveis, cerâmica, ferramentas, bijouterias, peles, cristais, p odutos agricolas e produtos artesanais daneses, em geral.

Revista do D.E.R. - Esta é uma revista publicada pelo Serviço de Transportes do Departamento de Estradas de Rodagem do Estado de São Paulo. Contém o exemplar de $n^{\text {ss }}$ 87-8 - Ano XXII setembro-dezembro de 1963, editado no Estado brasileiro de São Paulo, vários assuntos muito interessantes, ligados aos objetivos da revista, versando sôbre: pavimentação de estradas; sinalização pa:a veiculos em rodovias; sinalização preventiva ou definitiva; o trânsito na capital e seu crescente aumento de veiculos, etc.

Termina o exemplar com Noticias Rodoviárias, nacionais e internacionais. $O$ enderêço da presente publicação é Rua Riachuelo, 115 - $11^{\circ}$ andar, no Estado de São Paulo.

Revista de Engenharia do Estado da Guanabara - Orgão da Secretaria de Obras Públicas. Esta revista trata de assuntos técnicos do ramo da engenharia administrativa e genérica, servindo como veículo de divulgação das ocorrências arquiteturais dêsse estado-memb-o da federação brasileira. A capa do volume I, pertencente ao trimestre de janei-o-março de 1965 apresenta ampla fotografia da Avenida Nôvo Rio, uma das principais vias de penetração para o subúrbio carioca, ligando a Avenida Brasil à Avenida dos Democráticos e à Avenida Suburbana. As diversas obras já realizadas nessa pequena regiâo desde que passou a ser territór:o guanabarino, são focalizadas nesta revista, acompanhadas de explicação daqueles que nela militam e as planejam, por se tratar de publicação elaborada pelos engenheiros pertencentes ao serviço do referido Estado.

Revista de La Facultad de Ciencias Económicas $y$ de Administracion - O volume $\mathrm{n}^{\circ} 24$ de outubro de 1964, editado em Montevidéu, no Uruguai, apresenta os "Informes da Secretaria da CEPAL", a respeito da Conferência das Nações Un:das, sôbre Comércio e Desenvolv'mento na América Latina. E' extensa a relação de assuntos tratados em seu indice, cujo conteúdo pode ser resumido da seguinte maneira: 'além dos Informes já citados, constam, também, Conclusões da Reunião de Peritos Governamentais da América Latina; 
malis, a Carta de Alta Gracia, resultante de reunião efetuada em março de 1964, na Provincia de Córdoba, na Argentina. Fecha o volume a Ata final da Conferência das Nações Unidas sôbre Comércia e Desenvolvimento, de acôrdo com a versão definitiva adotada pela Conferência em sua XXXV Sessão Plenária, efetuada a 15 de junho de 1964. Em nota acrescida ao Indice, vem esclarecido que "as denominaçōes empregadas neste documento, e a forma em que apa. recem os dados que contém, não implicam, de parte da Secretaria das Nações UUnidas, juizo algum em tôrno da condição juridica de nenhum dos paises ou territórios, ou de suas autoridades, nem sequer diz respeito à delimitação de suas f:onteiras".

Kectista de Finanças Públicas - Publicaçãa do Conselho Técnico de Economia e Finanças do Ministério da Fazenda. Do Ano XXV. o n* 231 de janeiro de 1965 , se inicia com o Relatório que transcreve o Resumo das Atividades do Ano de 1964, do já citado Conselho. Apresenta êste volume uma sintese histórica e outra, da situação atual, além das normas financeiras e contábeis decorrentes da Lei $n$ 4.320-64, e no mesmo, se encontram anexados 52 quadros estatisticos.

Estuda a publicação mais os seguintes assuntos: um estudo do Orçamento Federal para 1965 pelo Contado- Raul Fontes Cotia; a Lei n* 4.595 de 31-12-64, que estabelece a Reforma Bancária e cria Conselho Monetário Näacional.

Ao final, a mesma publica o fndice Alfabético e Remissivo desto revista, relativo ao periodo de Janeiro de 1963 a dezembro de 1964, compilando os volumes de n* 225 e 230 .

$\mathrm{O}$ n* 232 de fevereiro de 1965 , apresenta, em abertura, uma exposição do Ministro Roberto Campos, sob o titulo "O Desafio do Desenvolvimento Econômico e da Justiça Social"
Divulga o mesmo número, o Anteprojeto de Código de Obrigações, tratando de Títulos de Crédito, lançado a público pelo $\mathrm{Mi}$ nistro da Justiça e Negócios Interiores, no Diário Oficial de 22 de fevereiro de 1965 , com a finalidade de receber sugestões, de acôrdo $\mathrm{com}$ o que dispõe o artigo $4^{4}$ do Decreto $n^{\circ} 1.490$ de 8-11-62. Fecha esta publicação um indice alfabético remissivo sôbre a Lei "n' 4.320 de 17-3-64 que dispõe normas gerais de direito financeiro aplicáveis aos o:çamentos e balanços.

Revista do IRB - Publicação bimestral do Instituto de Resseguros do Brasil, de $n^{*} 147$, de outubro de 1964. E' editada pelo Serviço de Relações Públicas do mencionado Instituto. Cuida, especificamente de assuntos que se enquadram nos objetivos dêsse órgão e matérias afins. No presente volume, tanto seu editorial quanto o artigo que se the segue, tratam do resseguro pe-centual no ramo Incêndio, quie êles consideram ser uma inovaçăo revolucionária simplificadora do processamento administrativo, matéria essa que vai amplamente explicada pelos Técnicos dêsse Instituto. Compõe-se de muitas outras seções essa publicação. $O$ exemplar $e_{m}$ causa registra o fato de 57 Irbiátios terem recebido distintivos por 20 anos de serviços prestados àquele Instituto. Outro volume referente a dezembro do mesmo ano, dedicou uma seção à Imprensa, a qual atende à epigrafe "Imprensa em Revista". $\mathrm{Na}$ sua seçấo intitulada Noticiário, vêm informados os acontecimentos ocorridos naquela autarquia.

Revista de Intendência da Aeronáutica - Esta revista apresenta, invariàvelmente, um editorial cujo assunto atende sempre à grande oportunidade do tema de que trata, versando êle, via de regra, em tôrno de assunto do interêsse do funcionalismo civil e militar. Possui mais, farta legislação que cuida 
também, de assuntos de natureza administrativa publicada, oficialmente, no bimestre anterior ao qual a Revista pertence. Apresenta, outrossim, tôda e qualquer regulamentação especifica do Ministério da Aeronáutica, e ainda, jurisprudência administrativa, variada. Recebemos no presente período o exemplar de n 159-60 do Ano $\mathrm{XV}$ referente ao bimestre novembro-dezembro de 1964 .

Revista do Sindicato Nacional da Indústria do Cimento - Temos em nossa redaçăo, presentemente, os exemplares de $n^{\text {" }} 131-3$, de setembro-outubro-novembro de 1964; e o de $n^{\prime}$ '134, de dezembro do mesmo ano, editados no Estado da Guanabara. O n* 131 é aberto com o registro do falecimento do Prof. Francisco Clementino de San Tiago Dantas, ocorrido a 6 de setembro de 1964. Fêz êsse brasileiro carreira na vida pública, tendo sido advogado, escritor, jornalista, administrador, deputado e professor da cátedra de Direito Civil, ocupando, posteriormente, a pasta de Ministro da Fazenda do Brasil. Uma fotografia nos mostra aquêle mineiro que também foi Ministro das Relações Exteriores, quando discursava no Sindicato Nacional do Cimento, em abril de 1956. o qual êle ajudou a fundar. em 1963, tendo sido seu Consultor Juridico.

Outro volume de n* 137-8 de março-abril de 1965 , expõe, como abe-tura de suas páginas o Relatório do exercício de 1964 , demonstrativo das atividades do Sindicato, além dos Balanços Gerais do exercício do ano findo, incluindo o parecer do Conselho Fiscal.

Revista da Universidade Católica de São Paulo - Esta é uma publicação trimestral que tem por finalidade difundir o pensamento católico e divulgar os resultados da investigação científica das Unidades Universitárias. Recebe ela colabo-ação dos professôres e dos alunos daquela Universidade, Con- tém, outrossim, análịses de livros, e uma seção pertencente à Assessoria Juridica de Reitoria, em que são comentados alguns pareceres. Termina com o registro de Publicações Recebidas pela Biblioteca Central. O presente volume apresenta, sob a autoria do Professor Haroldo Valladáo, um estudo em tôrno da personalidade do Papa, recentemente falecido, que se intitula "João XXIII, pater et $\mathrm{Ma}$ gister Gentium".

Revue Internationale des Sciences Administratives - Publiée par l'Institut International des Sciences Administratives. Esta revista é editada em três ediçóes separadas em linguas francesa, inglêsa e espanhola. 'E' uma revista típica de assuntos de administraçắo, de cooperaçấo técnica e de assistência econômica. Suas páginas registam sempre os mais selecionados articos sôbre Administração em geral, destacando-se aquêles que contêm meticulosos estudos e conceitos oriundos de pesquisas no campo da ciência da administraçăo.

$\mathrm{O}$ volume XXX - N. 3 1964, publicé trimestriellcment Bruxelles 4 - Belgique - Rue de la Charité, 25, consigna os sequintes artigos: 1) The Public Administration Division; of the United Nations: a brief history; 2) Hacia una Administración "eficiente y suficiente"; 3) Le nouveau stat des functionnaires en Espagne; 4) Major Issues in Professional Training for Public Administration; 5) La formation des cadres administratifs des pays en voie de développement: programmes et manière d'enseigner; 6) Administrativee Agencies and Courts: some patterns of inter-organizational relations; 7) Les tâches de la Science Administrative dans les pays socialistes.

Possuem, ainda, os exemplares desta publicação, normalmente, resumos em lingua inglesa e espanhola dos artigos publicados no respectivo volume. Apresenta, tam- 
bém, selecionada bibliografia, onde são feitos ligeiras criticas dos livros ali mencionados, e noticias bibliográficas, além de uma seção que comenta algumas obras mais detalhadamente. Termina êste volume com informações e noticias, e uma crônica sôbre o referido Instituto, à respeito de suas seçōes, seus membros e falando, ainda, no XIII Congresso Internacional de Ciências Administrativas.

Scala Internacional - Esta é uma revista mensal editada na Alemanha, em Frankfurt, ilustrada, da qual é distribuida no Brasil uma ediçắo luso-brasileira. Contém reportagens de diversos locais do mundo, principalmente das localidades situadas no pais de onde se origina. Dos dois exemplares que temos, agora, - de $n^{*} 5$ se refere a maio de 1965 e o de $n^{2} 6$, a junho do mesmo ano, aparecendo no primeiro citado, uma reportagem sôbre - Instituto de Pesquisa Espacial do Observatório de Bochum, que considera sua tarefa mais importante, o ensino da astronomia. Seu planetário pode projetar a posiçăo das estrêlas, em qualquer época, e dali, quem observar o cosmos, poderá verificar a presença de 9.000 estrêlas fixas, cinco planetas, o Sol, a Vila Láctea, e a Lua com suas manchas e mudanças de fases, tudo isso é informado numa reportagem sob o titulo "Mirante para o Universo".

La Scienza e la Tecrica della Organizzazione nella Pubblica Amministrazione - Revista trimestral de Ciência da Administração e de, Técnica aplicada. Revista exclusiva de assuntos de administração pủblica, divide-se em várias seções, que obedecem a uma nu-. meração em algarismos romanos, as quais debatem, pela natureza de seus titulos, os seguintes assuntos: Legislação e Documentação; Realização e orientação da Âdministtação Pública; Livros, Revistas, Jornais; outros fatos e outras idéias: Tribuna Liberal. Há uma seção, predecessora destas que se apre- senta com a epigrafe Artigos Originais, e nela aparecem todos os artigos assinados. Neste número, 4 do Ano XI, que é referente ao trimestre ottobre-diciembre, 1964 Milano, Italia, o artigo inicial tece comentários sôbre organização aplicada à administração pública, e diz que a administração institucional é atividade produtiva; diz ainda, que são controvertidos os conceitos de politica, administração, direçăo e organização. Afirma o mesmo prefácio que estão no campo da ciência da administraçăo, todos os problemas de Administração Pública, e outrossim, que podemos distinguir 3 categorias conceituais de Administração. Explica serem essas categorias vistas como instrumentalidade, como atuação, e também, de operatividade. E finda, fazendo votos para que todos êsses conceitos possam ser um dia suficientemente esclarecidos, pelo menos, os mais genéricos.

Sintese Politica, Económica e Social Orgăo oficial do Instituto de Estudos Politicos e Sociais da PUCRJ. Publicaçăo, trimestral, aparecem no n 25 do Ano VII, de janeiromarço de 1965, dois artigos assinados que são: 1) Tensões Sociais no meio rural brasileiro; 2) Estruturas sociais e paz social. A revista apresenta ainda, nas invariáveis seções que tendem ao seu título, o seguinte esquema: em Sintese Politica - "Reforma eleitoral e estatuto dos Partidos"; em Sintese Econômica - "A execução da política econômica do Govêrno"; em Sintese Social - "A Reforma da Previdência Social".

Sob a epígrafe Escrevem neste número, ela fornece os dados biográficos dos colaboradores do presente número, respectivamente: Wanderbilt Duarte de Barros; Mário G. Reis e Estanislau Fischlowitz. O indice dos artigos publicados no ano findo, de 1964, dividido por seções, figura no final do exemplar. 
SLIDENE - "O Transporte ferroviátio no Nordeste do Brasil". Livro editado pela Superintendência do Desenvolvimento do Nordeste, da Série Transportes - Setembro de 1962 - Recife, Estado de Peruambuco. E' autor do presente trabalho o Técnico em Transportes da Direção de Operações de Assistência Técnica das Nações Unidas, J. Rey Alvarez, sendo, porém, esclarecido que, relativamente ao teor das opiniốes nêle contidas, não representam elas, integral repetição do pensamento apresentado nas atas do Bureau de Operações de Assistência Técnica da ONU. Em seu prólogo, a presente publicação informa que sua finalidade é atualizar e completar os dois relatórios anteriores apresentados pelo autor, em 1958 para - antigo Conselho de Desenvolvimento do Nordeste, sôbre as estradas de ferro da região; e o outro, editado em 1960 pela SUDENE, sôbre a Rêde Ferroviária do Nordeste, que é a estrada de ferro mais importante entre as 7 que ali operam.

Uniăo dos Viajantes - Mensário social fundado em 20 de março de 1931. Este jornal pertence à Sociedade da União dos Caixeiros Viajantes. O $\mathrm{n}^{\circ} 4$ do Ano XXXIV é de abril de 1965, e vem da cidade de Santa Maria, no estado brasileiro do Rio Grande do Sul. Comunica-nos a realização das próximas eleições para a Diretoria daquela Sociedade, e a publicação de tôda a chapa elegivel, serâ apresentada no número vindouro. Do mesmo ano desta publicação, sâo os n $\mathrm{n}^{\text {s }} 5$ e 6 , referentes a maiojunlıo dêste ano, que apresenta o curriculo de cada candidato associado que concorrerá às eleições para a Diretoria da referida Uniăo. Em circular, explica a seus associados como devem votar, e mais adiante, expõe fotografias com os respectivos nomes e um histórico prufissional de cada candidato de ambas as chapas concorrentes à Diretoria da sociedade, como tam- bém, ao Conselho Fiscal, informandu que a eleição se iniciará em 1 de julho e terminará a 20 de setembro do corrente ano, podendo seus associados votarem por correspondência, encaminhada esta para d sede como para qualquer dos departamentos ou delegacias da mesma sociedade, com um dos delegados locais.

Universidade do Ceará - Anais - Tomo VI - 1960. Os Anais da Universidade são relativos às atividades desempenhadas pela mesina, no ano de 1959, e constam de um Relatório apresentado pelo Magnifico Reitor, Prof. Antônio Martins Filho, à Assembléia Universitária, realizada a 3 de março de 1960. A presente publicação foi editada pelo Serviço de Documentação, Estatistica e Divulgação, e pela Imprensa Universitária do Estado, contendo: Introduçăo; Ocorrências do ano de 1959; Plano de Atividades para 1960; Conclusões da I Parte dêstes Anais, sob o titulo "Universidade e Desenvolvimento"; esta, foi apresentada a título de aula magna. A segunda parte consta de Atas das Sessões do Conselho Universitário e de suas Resoluções, em 1960. A $3^{*}$ parte apresenta um 'Calendário de Acontecimentos", separado por meses.

Unuversidad - Esta é uma publicação da Universidad Nacional del Litoral, na República Argentina. Temos, presentemente, os exemplares de $\mathrm{n}^{\circ 8} 61$, referente aos meses de abril-junho de 1964; e 62, de julhosetembro do mesmo ano, editada na cidade de Santa Fé, na Argentina. Cada artigo nelas divulgado representa meticuloso estudo literocultural. Suas contra-capas comunicam que seus exemplares se destinam ao comentário do trabalho de pesquisa desenvolvido na Universidade, em assunto de Humanidades e Ciências e reflete seu pensamento sôbre o movimento cultural, clentífico e universitário. 
Utrecht Trade Fair - Boletim da Feira Permanente de Utrecht, com resumo sôbre os artigos expostos nos diversos stands daquela feira. Outros informes sôbre a exposição de máquinas e equipamentos mecânicos, motores, aparelhos de aplicações doméstica, material fotográfico, etc. encontram-se nesta publicação: News of Utrecht Trade Fair, referente a março de 1965 , e proveniente se Vredenburg.

Vida Universitária - Revista mensal publicada pela Comissão de Extensão da Universidade de Havana. Recolhe o Correio de Havana tôda a correspondência dessa universidade, que possui franquia postal na administração dos correios daquela cidade. $\mathrm{E}^{\prime}$ fundador da referida Universidade, o Dr. Clemente Inclan, sendo seu atual Reitor, o Prof. Elias Entralgo. Os quatro volumes que recebemos neste trimestre, mostram, solenidades, conferências, reuniōes, e outros fatos ali transcorridos, e săo: Ne 167-8 - julio-agosto de 1964; N. 169 - septiembre de 1964; Ni 170 - octubre de 1964; Nos 171-2 - noviembre-diciembre de 1964, editados na cidade de $\mathrm{Ha}$ vana. 